\title{
Comparison of Classical SEM and ESEM Protocols for Study of Conifer Embryogénie Tissues with Using Low Temperature Conditions of ESEM.
}

\author{
V. Neděla ${ }^{1}$, E. Tihlaříková ${ }^{1}$, J. Hřib $^{1}$, J. Runštuk $^{1}$ \\ 1. Department of Electron Microscopy, Institute of Scientific Instruments of ASCR, Brno, Czech Republic
}

Somatic or asexual embryogenesis is the process whereby genetically identical trees are produced through the production of embryo-like structures from somatic cells and are the primary enabling technology for all plant biotechnology products. A well-established and commonly used method for the study of plant samples is light optical microscopy. High resolution and depth of field of scanning electron microscopy (SEM) is necessary to the study of embryo micromorphology etc. Nevertheless, the SEM requires complex preparation processes to make the sample stable in vacuum conditions and also electrically conductive. Each step of sample preparation can cause various artifact formations and/or destructions of the finer features, especially in a case of plant early somatic embryos covered with a susceptible extracellular matrix (ECM).

The possibility to regulating moisture in the specimen chamber make the ESEM suitable for observation of susceptible biological samples as close to their native state as possible. Great potential of ESEM for investigation of plants was confirmed in the recent works of Popielarska-Konieczna et al. (2010). The samples are usually examined in high pressure conditions of ESEM with tendency to cool the samples to a temperature slightly higher than $0^{\circ} \mathrm{C}$ with negligible rate of moisture loss. This combination allows the thermodynamic stability of moist and fresh specimens to be controlled; having said that, different temperatures and gasses can provide better results in the case of specific samples or special experiments. A temperature around $-20^{\circ} \mathrm{C}$ allows to reach more suitable conditions for the study of conifer embryos, as was shown by Neděla et al. (2012).

The aim of this paper is to compare our method for ESEM study of native plant samples in a cooled state free of any preparations with conventional SEM and ESEM protocols.

The embryogenic cultures of Norway spruce (Picea abies (L.) Karst.) were obtained from the collection of Mendel University (Brno), maintained on a medium described by Havel and Durzan (1996) and sub-cultured in 10-14 day periods in the dark at $23 \pm 1{ }^{\circ} \mathrm{C}$.

The samples for SEM observation (Figure 1 A,B) were fixed for 2 hours in 4\% buffered formaldehyde (0.1 M phosphate buffer, $\mathrm{pH}$ 7.2), dehydrated through graded ethanol series and freeze-dried using t-Butyl alcohol, gold sputter coated and observed using SEM JEOL JSM-6700F.

The fully native embryogenic tissues were placed in a small water droplet (approx. $2 \mu 1$ ) on the cooling Peltier stage with silicone surface in our non-commercial ESEM AQUASEM II. The environment conditions were selected as follows:

1. The samples were observed under conditions recommended for wet observation in $\operatorname{ESEM~}\left(5^{\circ} \mathrm{C}\right.$, water vapor pressure $930 \mathrm{~Pa}$ ). Results are displayed in Figure $1 \mathrm{C}, \mathrm{D}$.

2. Then the samples were observed under a temperature around $-20^{\circ} \mathrm{C}$ and air was used instead of water vapor. Samples are imaged in Figure $1 \mathrm{E}, \mathrm{F}$. 
Our results demonstrate that ESEM is a very useful method in the study of native coniferous samples and the presented method has extended previous ESEM observation based on the specific hardiness of plant samples on low temperatures around $-20^{\circ} \mathrm{C}$. Nevertheless, low temperature may impose stress due to cell and tissue dehydration during the freezing of cellular water and intracellular or extracellular ice formation in the intercellular space so the conditions of ESEM observation have to be carefully examined and selected.
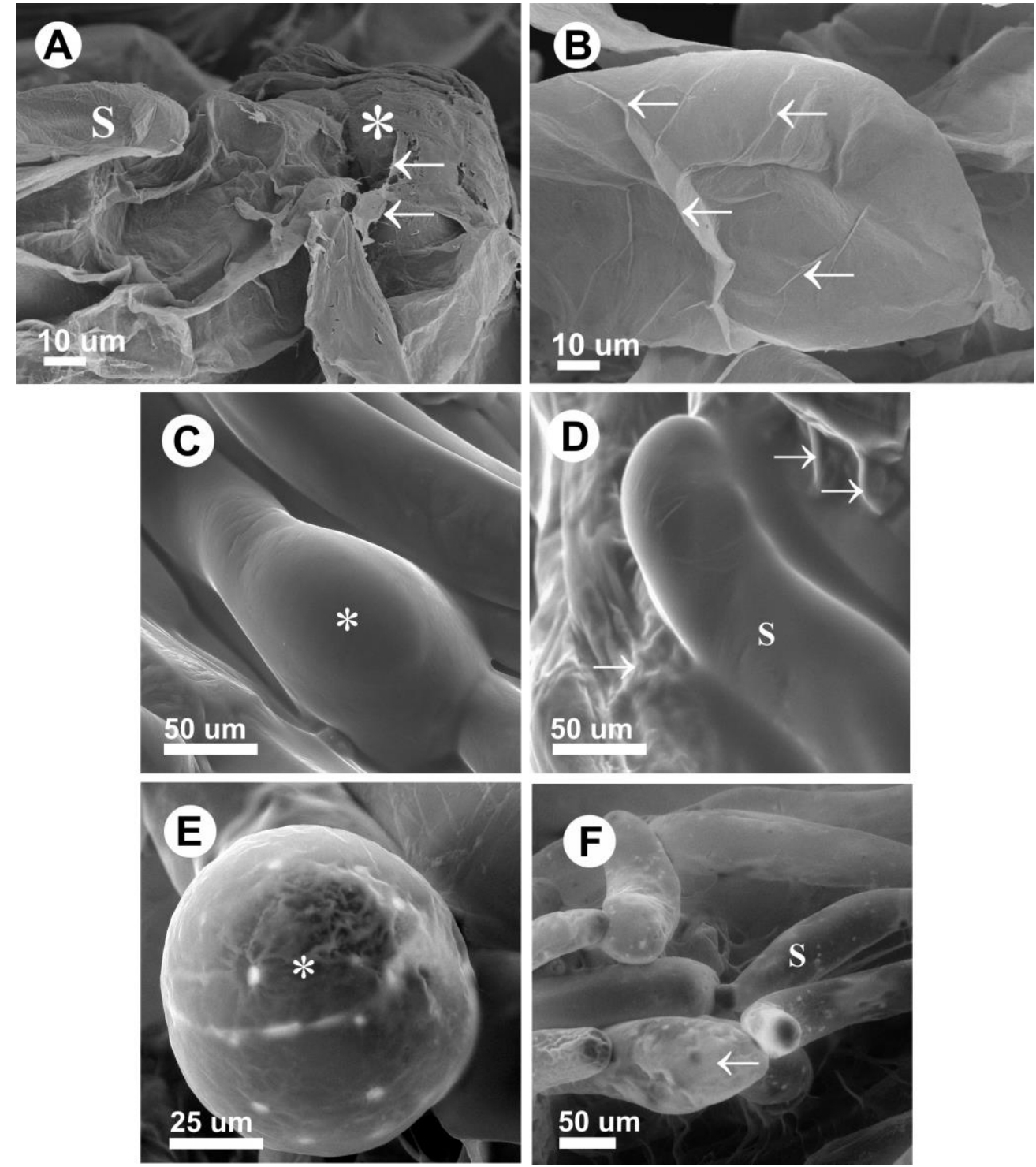

Figure 1: The embryonic tissue of Picea abies. A,B: The sample observed in SEM, accelerating voltage 5 $\mathrm{kV}$ and the working distance $15 \mathrm{~mm}$. C,D: The sample observed in classical ESEM conditions $\left(5^{\circ} \mathrm{C}, 930\right.$ $\mathrm{Pa}$ water vapor). E,F: The sample observed using our low temperature protocol $\left(-20^{\circ} \mathrm{C}, 400 \mathrm{~Pa}\right.$ air $) . \mathbf{S}-$ suspensor cell, arrow - extracellular matrix, symbol - embryogenic head

\section{References:}

[1] V Neděla et al, Biologia Plantarum 56(3) (2012) p. 595.

[2] M Popielarska-Konieczna et al, Protoplasma 247 (2010) p. 121.

[3] L Havel and DJ Durzan, Int. J. Plant. Sci. 157 (1996) p. 8.

[4] This work was supported by the Grant Agency of the Czech Republic: grant No. GA 14-22777S and Ministry of Education, Youth and Sports of the Czech Republic: CZ.1.07/2.3.00/20.0103 and LO1212 together with the European Commission (ALISI No. CZ.1.05/2.1.00/01.0017). 